\title{
ANÁLISE DA FLEXIBILIDADE NO PROGRAMA "MINHA CASA MINHA VIDA": O CASO DO LOTEAMENTO SUCESSO BRASIL, UBERLÂNDIA
}

\author{
VILLA, Simone Barbosa \\ Universidade Federal de Uberlândia, e-mail: simonevilla@ufu.br \\ STEFANI, Ana Carolina de Oliveira \\ Universidade Federal de Uberlândia, e-mail: carolstefani97@gmail.com \\ OLIVEIRA, Natália Fleury Guedes de \\ Universidade Federal de Uberlândia, e-mail: nfleuryg@gmail.com
}

\begin{abstract}
RESUMO
Quando os programas habitacionais do governo tentam resolver o déficit habitacional nacional, os baixos padrões de qualidade nas unidades ofertadas resultam em espaços inadequadas para seus habitantes, obrigando-os a fazer mudanças em edifícios pouco resilientes, que não estão necessariamente preparados para a adaptação, levando ao desperdício de material e ineficiência de recursos. A partir desse cenário, a pesquisa de iniciação científica "Resiliência e adaptabilidade no loteamento Sucesso Brasil: avaliação, análise e mapeamento a partir da avaliação pós-ocupação e coprodução (ação 1 e 2 )" teve como objetivo principal implementar e potencializar a resiliência e a adaptabilidade de Conjuntos Habitacionais de Interesse Social através de técnicas de Avaliação pós-ocupação e Coprodução em estudo de caso localizado em Uberlândia. O presente artigo apresenta parte dos resultados obtidos na pesquisa, relatando um estudo de caso baseado nos resultados de APO, com enfoque para o aspecto da flexibilidade das unidades habitacionais. Desenvolvido pelo programa "Minha Casa Minha Vida", o projeto possui ambientes estáticos e pouco flexíveis, que atendem de forma precária as reais necessidades de transformação dos moradores. Apesar disso, nota-se a presença de estratégias de flexibilidade implementadas de forma intuitiva pelos moradores. A metodologia utilizada foi a APO - a partir da coleta de dados, questionários com os moradores, walkthroughs e medições de desempenho. Dessa forma, o estudo visa promover uma diferença real e prática aos residentes no bairro e, futuramente, fornecer orientações detalhadas para o projeto de habitação mais adaptável e resiliente em um contexto local.
\end{abstract}

Palavras-chave: Flexibilidade, Habitação de Interesse Social, Avaliação Pós-Ocupação.

\begin{abstract}
When government housing programs attempt to solve the national housing deficit, the lowquality standards set out in the units result in highly inadequate spaces for their inhabitants, forcing them to make changes to buildings that are not resilient, which are not necessarily ready for adaptation, leading to material waste and resource inefficiency. From this scenario, the scientific initiation research "Resilience and adaptability in the Sucesso Brasil allotment: evaluation, analysis and mapping from the post-occupation evaluation and coproduction (action 1 and 2)" had as main objective to implement and enhance resilience and the adaptability of Housing Set of Social Interest through techniques of Post-occupation Evaluation and Co-production in a case study located in Uberlândia. The present article presents part of the results obtained in the research, reporting a case study based on the results of APO, focusing on
\end{abstract}

VILLA, S. B.; STEFANI, A. C. O.; OLIVEIRA, N. F. G. Análise da flexibilidade no conjunto habitacional de interesse social do Programa "Minha Casa Minha Vida": o caso do loteamento Sucesso Brasil, Uberlândia. In: SIMPÓSIO BRASILEIRO DE QUALIDADE DO PROJETO NO AMBIENTE CONSTRUÍDO, 6., 2019, Uberlândia. Anais... Uberlândia: PPGAU/FAUeD/UFU, 2019. $\quad$ p. $892-905 . \quad$ DOI https://doi.org/10.14393/sbqp 19083. 
the flexibility aspect of housing units. Developed by the "Minha Casa Minha Vida" program, the project has static and non-flexible environments that precariously address the real transformation needs of the residents. Despite this, it is notable the presence of flexibility strategies implemented in an intuitive way by the residents. The methodology used was the APO - from the data collection, questionnaires with the residents, walkthroughs and performance measurements. Thus, the study aims to promote a real and practical difference to residents in the neighborhood and, in the future, provide detailed guidelines for the most adaptable and resilient housing project in a local context.

Keywords: Flexibility, Housing of Social Interest, Post-Occupational Assessment.

\section{INTRODUÇÃO}

A partir do atual cenário mundial e suas mudanças climáticas e sociais, as estratégias de organização urbana devem ser urgentemente revistas a fim de se adaptarem às novas exigências do ambiente, de modo que consigam reduzir os impactos ambientais e desenvolver a capacidade de se adaptar ao espaço em que estão inseridos e as diferentes necessidades de cada morador. Nesse sentido, os projetos e obras em andamento passam por uma série de dificuldades para tentar atingir esses objetivos, tais como: encontrar técnicas e materiais de qualidade e que sejam funcionais; além de adaptar as construções para resistir à comportamentos climáticos e ambientais - tudo isso somado ao grande desafio de descobrir formas mais acessíveis para construir, a fim de diminuir o grande déficit habitacional que existe na maioria dos países em desenvolvimento, principalmente (VILLA, et al., 2017; AMORE; SHIMBO; RUFINO, 2015).

Como consequência desse impasse, alguns programas governamentais tentam melhorar a qualidade de vida daqueles que não tem acesso a moradia e se encontram em condições precárias, a partir da construção de conjuntos habitacionais. Ao fazer isso, no entanto, o que se observa são obras com materiais e técnicas precárias, além da execução grosseira e um projeto arquitetônico pouco flexível, obrigando diferentes tipologias familiares a fazerem mudanças em edifícios pouco resilientes que não estão necessariamente preparados para a adaptação, o que leva ao desperdício de material e ineficiência de recursos.

O conceito de "edifício resiliente" pode ser entendido como aquele que é capaz de se adaptar ou recuperar a partir de diferentes impactos (naturais, sociais, físicos). Tal significado foi adaptado para a área de arquitetura, e seu conceito tradicional está associada à capacidade de um sistema em absorver distúrbios e reorganizar-se quando sujeito a alterações, e ao mesmo tempo ser capaz de manter as suas funções essenciais (WALKER et al., 2004; THACKARA, 2008). De acordo com Vital (2012), "(...) desenvolver o grau de resiliência de um sistema urbano significa aprimorar o seu processo de superação de adversidades por meio de uma condição de adaptação que, inicialmente, reflete a capacidade do ambiente em administrar conflitos para manter-se em equilíbrio nas duas dimensões, social e ecológica." - de forma que o termo "sistema urbano" pode ser substituído por "habitação de interesse social", nesse caso.

Concomitantemente, a flexibilidade é entendida como a capacidade do espaço em adaptar-se de acordo com os usos praticados pelos moradores de modo a responder as suas necessidades e expectativas com eficácia e em condições de segurança física. Em outras palavras, é a capacidade do 
espaço físico se adaptar ao processo dinâmico do habitar (DIGIACOMO, 2004; SZÜCS, 1998). Pode-se afirmar, portanto, que a flexibilidade é um atributo facilitador para conferir resiliência. Nesse sentido, é fato que o PMCMV possui projetos cujos ambientes são pouco flexíveis, mas, apesar disso, as análises realizadas apontam que os moradores, por necessidade e resiliência, formulam estratégias intuitivas para superar as limitações impostas, criando alternativas para adaptação do espaço.

A partir desse cenário, a pesquisa "Resiliência e adaptabilidade no loteamento Sucesso Brasil: avaliação, análise e mapeamento a partir da avaliação pós-ocupação e coprodução (ação 1 e 2)" teve como objetivo principal implementar e potencializar a resiliência e a adaptabilidade de Conjuntos Habitacionais de Interesse Social através de técnicas de Avaliação pós-ocupação e Coprodução em estudo de caso localizado em Uberlândia. O tema abordado vai de encontro com as proposições das principais agendas urbanas globais: a Nova Agenda Urbana (NUA) - Habitat III de 2017 , os Objetivos de Desenvolvimento Sustentável de 2015 e a Agenda 2030; os quais são unânimes na definição da resiliência como a força motriz para o combate à vulnerabilidade urbana. Dos objetivos apresentados pelas agendas, destaca-se aqui o "Objetivo 11 - Tornar as cidades e os assentamentos humanos inclusivos, seguros, resilientes e sustentáveis". Assim, o presente artigo apresenta parte dos resultados obtidos na pesquisa, relatando a etapa de APO realizada no estudo de caso enfocando o aspecto da flexibilidade. A pesquisa se insere em um projeto maior em curso intitulado "[RES_APO 2 e 3] Resiliência e adaptabilidade em conjuntos habitacionais sociais através da avaliação pós-ocupação e coprodução"2.

O estudo visa avaliar e analisar o atributo da flexibilidade espacial no contexto da habitação social, como meio de conferir resiliência ao ambiente construído. Além disso, espera-se promover uma diferença real e prática aos residentes no bairro e, futuramente, fornecer orientações detalhadas para o projeto de habitação mais adaptável e resiliente em um contexto local. Além disso, as análises feitas auxiliam no desenvolvimento das coproduções em curso - em outras palavras, os resultados levantados ajudam a formular atividades participativas (coproduções), que por sua vez tem o objetivo de conscientizar a comunidade sobre a importância de um projeto resiliente e desenvolver estratégias mais elaboradas para adaptação das casas.

\section{AVALIANDO A FLEXIBILIDADE NO LOTEAMENTO SUCESSO BRASIL}

\subsection{Objeto de estudo}

A habitação de interesse social PMCMV em análise encontra-se no bairro Shopping Park, na cidade de Uberlândia, sendo atualmente formada por 12 residenciais. O estudo em questão trata de um recorte do Residencial Sucesso Brasil. De acordo com a Prefeitura, o investimento atendeu cerca de 3.632 famílias com faixa de renda até $R \$ 1.850,00$, e cada unidade entregue em 2012 a um custo de $R \$ 39.790,00$, por meio de sorteio público.

Tratam-se de casas geminadas dispostas de duas a duas em um quarteirão de dimensão padrão $\left(200 \mathrm{~m}^{2}\right)$, totalizando cerca de $36 \mathrm{~m}^{2}$ construídos para cada habitação. No projeto, a disposição de ambientes se dá de maneira idêntica: sala, cozinha, dois quartos, banheiro e uma lavanderia externa; exceto para as unidades destinadas as pessoas com deficiência. As casas possuem uma 
pare de compartilhada, e o sistema construtivo utilizado é radier de concreto e alvenaria de tijolo cerâmico. Tudo foi pensado para diminuir os custos, e o resultado são residências com materiais precários e execução de baixíssima qualidade.

\subsection{Metodologia}

RESILIÊNCIA E CAPACIDADE ADAPTATIVA

capacidade de responder, absorver

adaptar-se a diferentes impactos, impostos e/ou imprevistos (natural-

climáticos, socioeconômicos, físicos) e demandas extras

VULNERABILIDADE

sensibilidade do sistema em relação à ameaças específicas, associada à capacidade de adaptação das populações e instituições expostas
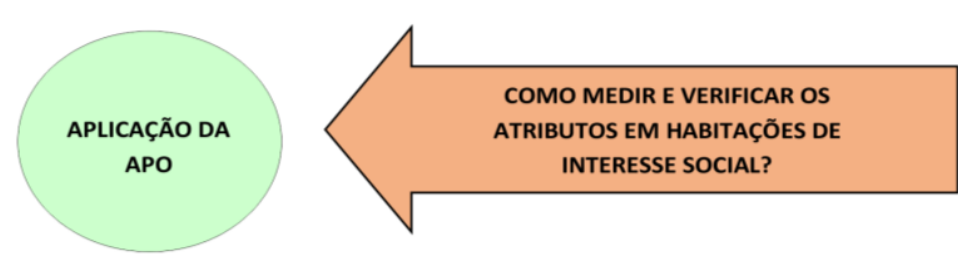

ADEQUAÇÃO AMBIENTAL

Energia, lixo, água, materiais/sistemas

ADEQUAÇÃo CLIMÁTICA

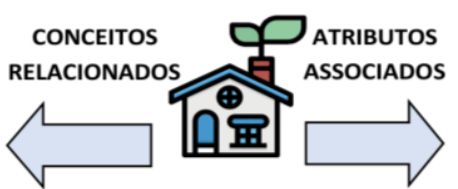

CASA RESILIENTE

Estanqueidade, resistência, conforto

ENGAJAMENTO

Fazer parte, compartilhar, comunicação, motivação, segurança

\section{BEM-ESTAR}

Continuar aprendendo, tomar conhecimento, doar, ser ativo, conectar FLEXIBILIDADE

Adaptabilidade, multifuncionalidade, variabilidade, conversibilidade

ACESSIBILIDADE

Mobilidade, design universal, acesso aos equipamentos sociais, acesso à

infraestrutura

Figura 1 - Infográfico: Contextualização geral da pesquisa Fonte: VILLA (2018), adaptado pelas autoras

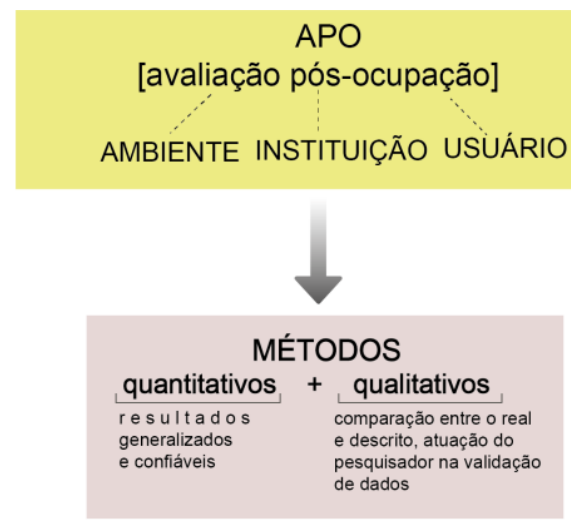

verificar a qualidade habitacional no empreendimento

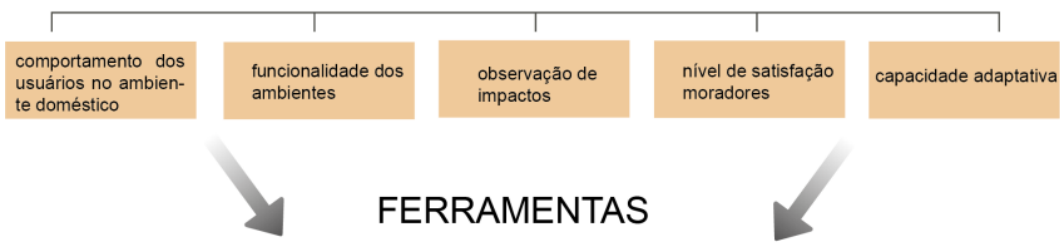

COLETA DE DADOS

( questionário)

Conjunto de perguntas fechadas para avaliar a maneira comportamental dos usuários e a forma de apropriação dos espaços, bem como os niveis

próprias moradias e o entorno que se insere.

\section{WALKTROUGH}

Coleta dados multidisciplinares do ambiente construido a partir de um reduzido espaço de tempo, associando análises de desempenho do ambiente e percepção dos pesquisadores.

Figura 2 - Infográfico: Resumo da metodologia -

Fonte: Autoras (2019) 


\section{Quadro 1 - Métodos utilizados}

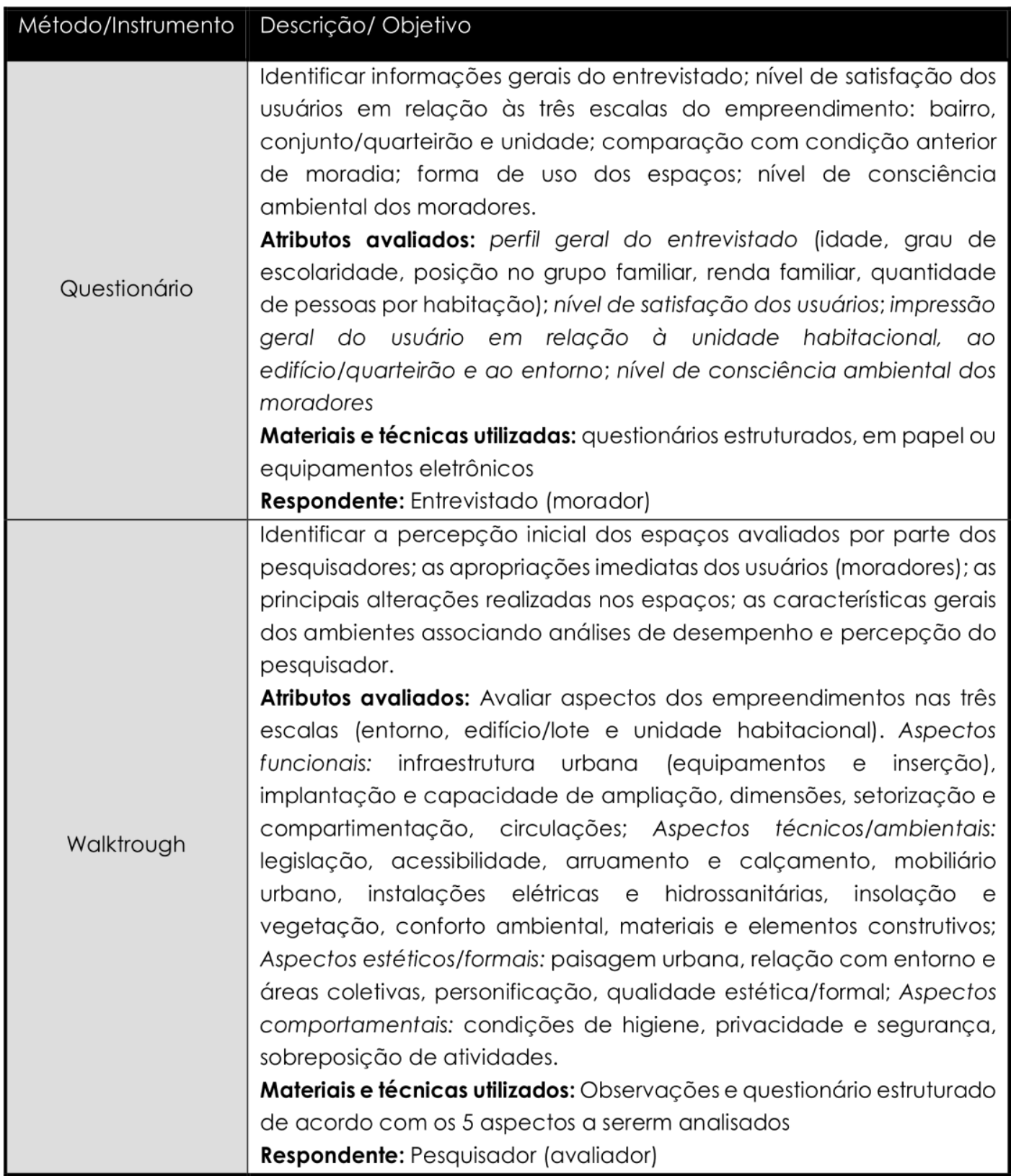

Fonte: VILLA (2018), adaptado pelas autoras

A Avaliação Pós Ocupação (APO) caracteriza-se por um conjunto de métodos utilizados na avaliação de desempenho e uso em edificações, que abrange o ponto de vista tanto dos usuários quanto dos especialistas. É uma ferramenta de pesquisa já extremamente alicerçada na área da construção civil tanto nacionalmente (ELALI; VELOSO, 2006; ORNSTEIN; VILLA; ONO, 2010; VILLA; ORNSTEIN, 2013; VOORDT; WEGEN, 2013; VILLA, 2015) como internacionalmente (LEAMAN; STEVENSON; BORDASS, 2010; PREISER; VISCHER, 2005; MALLORY-HILL; PREISER; WATSON 2012), sendo uma das principais ferramentas de base para essa pesquisa. A partir dela, é possível conceber um banco de dados com informações que verificam a qualidade habitacional, analisam o comportamento dos usuários no ambiente doméstico, inspecionam a funcionalidade dos ambientes, avaliam o nível de satisfação dos moradores e, afinal, observam os impactos, vulnerabilidades e capacidades adaptativas incidentes sobre o sistema. 
Quadro 2 - Matriz de Impactos, Vulnerabilidades e Capacidades Adaptativas

\begin{tabular}{|c|c|c|c|c|c|}
\hline \multirow{2}{*}{ Ordem analisada } & \multirow{2}{*}{ Aspectos } & \multicolumn{2}{|c|}{ Exemplos dos principais impactos * } & \multirow{2}{*}{$\begin{array}{l}\text { Vulnerabilidades* } \\
\text { observadas na } \\
\text { [RES_APO 1] }\end{array}$} & \multirow{2}{*}{$\begin{array}{l}\text { Capacidades } \\
\text { adaptativas* } \\
\text { observadas na } \\
\text { [RES_APO 1] }\end{array}$} \\
\hline & & Impostos & imprevistos & & \\
\hline Socioeconômica & $\begin{array}{l}\text { Demografia, dados } \\
\text { socioeconômicos, } \\
\text { violência, segurança } \\
\text { pública, educação, lazer } \\
\text { e cultura, saúde }\end{array}$ & $\begin{array}{l}\text { *a proposta não } \\
\text { considera a } \\
\text { diversidade de } \\
\text { perfis familiares } \\
\text { existentes; } \\
\text { *o projeto se insere } \\
\text { em área periférica } \\
\text { da cidade, } \\
\text { desprovida de } \\
\text { urbanidade }\end{array}$ & $\begin{array}{l}\text { *alto consumo de } \\
\text { tempo livre } \\
\text { envolvido na } \\
\text { realização de } \\
\text { reformas } \\
\text { *acúmulo de } \\
\text { rejeitos/materiais } \\
\text { de construção em } \\
\text { terrenos públicos e } \\
\text { privados }\end{array}$ & $\begin{array}{l}\text { *evolução não } \\
\text { sadia dos perfis } \\
\text { familiares em } \\
\text { relação à casa } \\
\text { *falta de } \\
\text { oportunidade de } \\
\text { trabalho locais e } \\
\text { distância em } \\
\text { relação ao centro } \\
\text { da cidade }\end{array}$ & $\begin{array}{l}\text { *iniciativa do } \\
\text { morador em realizar } \\
\text { reformas para } \\
\text { acomodar suas } \\
\text { necessidades } \\
\text { *os moradores } \\
\text { realizam trabalhos } \\
\text { extras para } \\
\text { complementação } \\
\text { da renda ou como } \\
\text { renda principal } \\
\text { (como cozinhar } \\
\text { para fora, } \\
\text { artesanato) }\end{array}$ \\
\hline Natural-climática & $\begin{array}{l}\text { Vegetação, topografia, } \\
\text { fontes de água/fluxos, } \\
\text { poluição/lixo, consumo } \\
\text { de água e energia, } \\
\text { produção de alimentos, } \\
\text { clima }\end{array}$ & $\begin{array}{l}{ }^{*} \text { carência de } \\
\text { arborização } \\
\text { urbana intra e } \\
\text { extra-lote } \\
\text { *projeto não prevê } \\
\text { elementos } \\
\text { arquitetônicos e } \\
\text { materiais que } \\
\text { absorvam ou } \\
\text { resistam aos } \\
\text { impactos das } \\
\text { mudanças } \\
\text { climáticas do } \\
\text { clima }\end{array}$ & $\begin{array}{l}\text { *altas taxas de } \\
\text { impermeabilização } \\
\text { do solo ( } 50 \% \text { nã̃ } \\
\text { dispõe dos } 20 \% \text { de } \\
\text { área permeável } \\
\text { recomendados) } \\
\text { *construção de } \\
\text { rampas para } \\
\text { vencer desniveis }\end{array}$ & $\begin{array}{l}\text { *falta de contato } \\
\text { com a natureza e } \\
\text { os benefícios que a } \\
\text { mesma pode trazer } \\
\text { para a saúde } \\
\text { *plantio de árvores } \\
\text { inviabilizado pela } \\
\text { pavimentação dos } \\
\text { lotes e construção } \\
\text { de rampas que } \\
\text { ocupam toda a } \\
\text { calçadas }\end{array}$ & $\begin{array}{l}\text { *72,9\% tem plantas } \\
\text { em casa e } 67,5 \% \\
\text { sentem falta de } \\
\text { áreas vegetadas em } \\
\text { casa }\end{array}$ \\
\hline Física-arquitetônica & $\begin{array}{l}\text { Projeto (formas/ } \\
\text { dimensões/ flexibilidade/ } \\
\text { adaptabilidade), } \\
\text { materiais e sistema } \\
\text { construtivo, layout interno } \\
\text { (funcionalidade), } \\
\text { conforto (ruido, } \\
\text { temperatura, umidade, } \\
\text { iluminação, privacidade) }\end{array}$ & $\begin{array}{l}\text { *casa-embrião em } \\
\text { técnica construtiva } \\
\text { autoportante não } \\
\text { prevê/indica } \\
\text { sentido de } \\
\text { ampliação } \\
\text { *necessidade de } \\
\text { estocagem não foi } \\
\text { bem } \\
\text { comtemplada na } \\
\text { proposta do } \\
\text { projeto }\end{array}$ & $\begin{array}{l}\text { *iluminação e } \\
\text { ventilação dos } \\
\text { cômodos } \\
\text { prejudicada após } \\
\text { ampliações } \\
\text { *alterações nas } \\
\text { necessidades de } \\
\text { mobilidade dos } \\
\text { moradores - } \\
\text { desemprego: } \\
\text { adaptação de } \\
\text { residências para } \\
\text { abertura do } \\
\text { próprio negócio }\end{array}$ & $\begin{array}{l}\text { *dificuldade de } \\
\text { adaptação à } \\
\text { moradia } \\
{ }^{*} \text { dificuldade para } \\
\text { realização de } \\
\text { tarefas diárias }\end{array}$ & $\begin{array}{l}\text { *as dimensões do } \\
\text { lote para frentes e } \\
\text { fundos e baixa } \\
\text { densidade do } \\
\text { conjunto favorecem } \\
\text { a realização de } \\
\text { ampliações, porém } \\
\text { importa salientar } \\
\text { que as } \\
\text { características do } \\
\text { projeto original não } \\
\text { conferem a ela a } \\
\text { propriedade de } \\
\text { adaptabilidade }\end{array}$ \\
\hline Física-urbanística & $\begin{array}{l}\text { Serviços (eletricidade, } \\
\text { esgoto, Tl/eletrônicos, } \\
\text { custo + oferta), } \\
\text { infraestrutura (água, } \\
\text { esgoto, águas pluviais, } \\
\text { eletricidade, } \\
\text { pavimentação, } \\
\text { iluminação, lixo, serviços } \\
\text { de limpeza, internet, } \\
\text { mobilidade) }\end{array}$ & $\begin{array}{l}\text { *baixa qualidade } \\
\text { dos materiais das } \\
\text { calçadas e } \\
\text { dimensões } \\
\text { reduzidas } \\
\text { prejudicando a } \\
\text { acessibilidade } \\
\text { *as lixeiras } \\
\text { individuais são } \\
\text { insuficientes em } \\
\text { tamanho e } \\
\text { formato e não } \\
\text { promovem a } \\
\text { contenção } \\
\text { adequada do lixo }\end{array}$ & $\begin{array}{l}\text { *acúmulo de lixo } \\
\text { no bairro e } \\
\text { proliferação de } \\
\text { animais } \\
\text { indesejáveis } \\
\text { *utilização do leito } \\
\text { carroçável para } \\
\text { deslocamento de } \\
\text { pedestres }\end{array}$ & $\begin{array}{l}{ }^{*} \text { dificuldade de } \\
\text { acesso a pessoas } \\
\text { com mobilidade } \\
\text { reduzida } \\
\text { *suscetibilidade a } \\
\text { atropelamentos }\end{array}$ & $\begin{array}{l}\text { Não foram } \\
\text { observadas }\end{array}$ \\
\hline
\end{tabular}

Fonte: BORTOLLI (2018), adaptado pelas autoras

O walktrough é utilizado para coletar dados do ambiente em estudo, associando análises de desempenho do ambiente e percepção dos pesquisadores. Realiza-se um percurso na unidade habitacional mediante à um roteiro pré-estabelecido, no qual o pesquisador consegue identificar atributos relevantes para qualificar a avaliação, que estão identificados no Quadro 1. 
A fim de viabilizar a coleta de dados a campo, foi determinado um universo amostral de 40 residências para a aplicação do questionário. Em relação ao walkthrough a amostra foi reduzida a 7 unidades, devido a própria receptividade dos usuários e os demais prazos da pesquisa em curso.

Com base nos resultados obtidos durante etapas anteriores da pesquisa foi possível observar as fragilidades e potencialidades que condicionam, de maneira geral, a resiliência no Residencial Sucesso Brasil. Foram concebidos instrumentos de avaliação com base na organização das informações obtidas na fase anterior em forma de uma Matriz de impactos, vulnerabilidades e capacidades adaptativas - que auxiliaram na estruturação dos novos instrumentos de análise, melhor direcionados para aspectos de interesse apontadas pela matriz. Esses aspectos, por sua vez, foram organizados a partir das 4 ordens de análise elencadas e seus aspectos (Quadro 2). O artigo em questão aborda a ordem Física-Arquitetônica, cujos aspectos estão associados ao atributo flexibilidade.

A partir de perguntas específicas, o questionário mostra identifica o comportamento dos usuários e a forma de apropriação dos espaços, bem como os níveis de satisfação em relação às próprias moradias e o entorno que se insere. Esse método é bastante utilizado, uma vez que sua aplicação é simples e eficiente. De modo geral, ele funciona, pois é possível "descobrir regularidades entre grupo de pessoas pela comparação das respostas dadas a um mesmo conjunto de perguntas feitas para um número representativo e significativo de respondentes" (REIS; LAY, 1994 apud IMAI; FAVORETO, 2002, p.436).

\subsection{Resultados obtidos}

Tratando-se da unidade habitacional em análise, entende-se que a tipologia tem como base uma família nuclear com 2 filhos. Apesar de $35 \%$ das famílias entrevistadas serem constituídas por 4 membros, existem famílias expandidas, com a presença de novos integrantes (genro, nora) e netos (Gráfico 1). Outra configuração encontrada são famílias monoparentais, geralmente a mãe como gestora da casa, com um número de 3 a 4 filhos, como mostram os resultados dos gráficos 1 e 2 oriundos do questionário aplicado à comunidade.

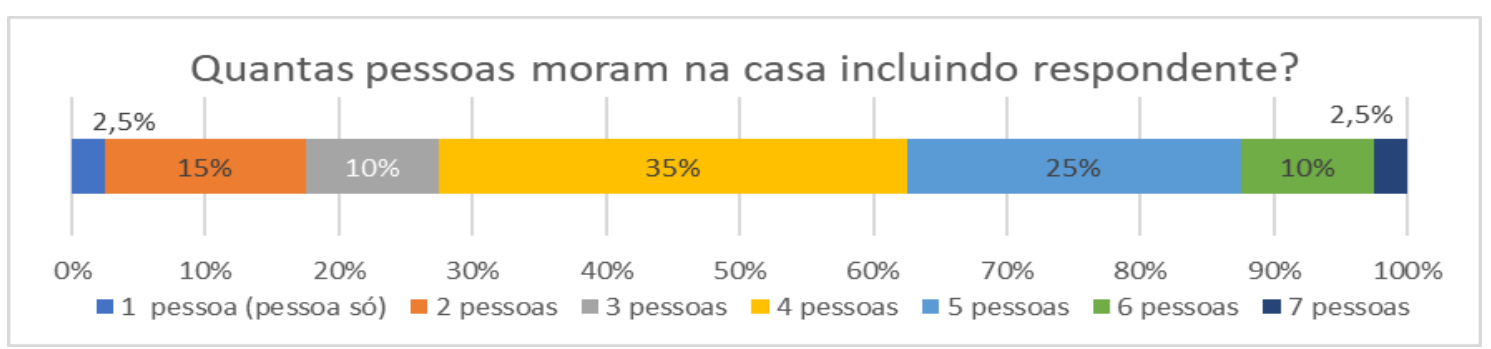

Gráfico 1 - Quantidade de pessoas por residência -

Fonte: Autoras (2019)

Comparando esse panorama com o modelo previsto pelo programa, confirma-se a falta de concordância entre a tipologia e a família inserida. A estrutura rígida de organização da planta impede a modificação do layout para atender estruturas familiares diferentes, prejudicando o conforto e bemestar dos usuários. Esses se acomodam como podem e muitas vezes tem espaços de estocagem, circulação e ventilação obstruídos por móveis ou 
paredes que são erguidas em processos de reformas, na tentativa de ampliar os cômodos e reaproveitar o que já existe.

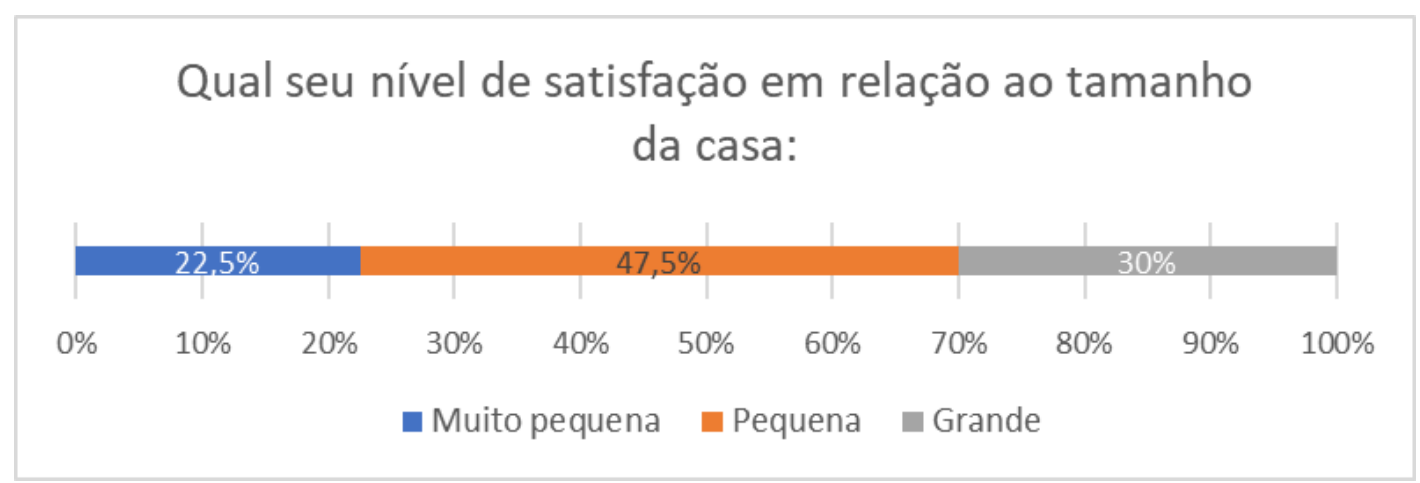

Gráfico 2 - Nível de satisfação em relação ao tamanho da residência Fonte: Autoras (2018)

Percebe-se, por isso, que as possibilidades de ampliação e flexibilidade da planta são mínimas. O sistema construtivo engessado impede a remoção de paredes para reorganização dos cômodos, que por sua vez possuem dimensões que não favorecem a disposição do mobiliário desejado. As ampliações apenas são possíveis na frente ou nos fundos do lote - respeitando os afastamentos mínimos, o que muitas vezes resulta em cômodos com janelas obstruídas e sem entrada de luz natural.

A fim de realmente analisar a forma como os moradores lidam com tal situação, é importante verificar os dados coletados a partir do questionário e dos walkthroughs. Inicialmente, apesar de $30 \%$ dos entrevistados considerarem a residência espaçosa (Gráfico 2), quase $90 \%$ das moradias já passou por alguma modificação (Gráfico 3), cujos $55 \%$ dos que realizaram reforma revelaram que o motivo de realização foi o seu tamanho (Gráfico 4). Essa contradição acontece pois muitas famílias provém de situações muito piores de habitação, e a oportunidade da conquista de uma moradia vai muito além de suas expectativas.

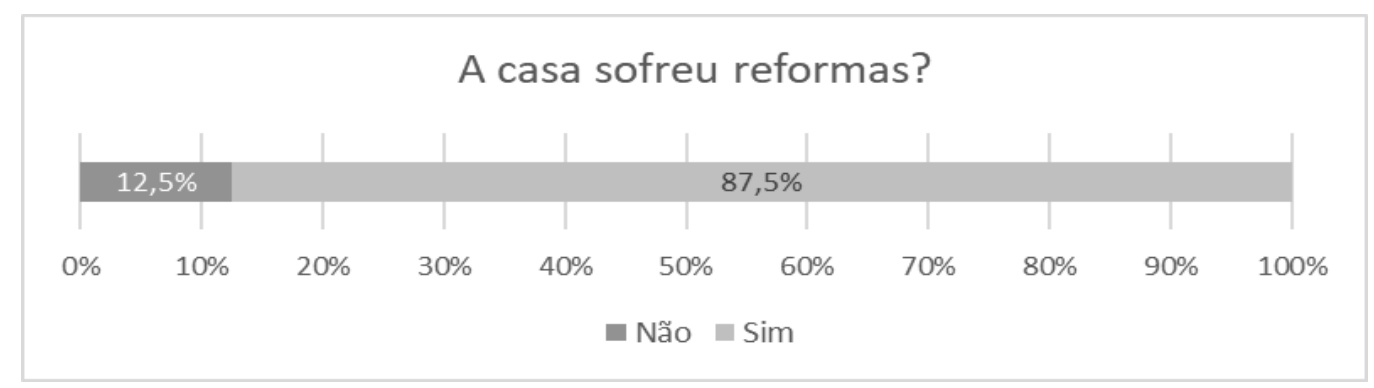

Gráfico 3 - Porcentagem de residências que já sofreram reformas Fonte: Autoras (2018)

Paralelo à essa questão está a forma que o projeto original prevê o arranjo da mobília e como ela realmente acontece, em relação à adequação com as dimensões dos espaços - que são mínimas. Nesse sentido, através do Gráfico 5, é possível perceber que as opiniões encontram-se divididas, pois $50 \%$ dos entrevistados estão insatisfeitos com o tamanho da residência, mas a outra metade acredita que a tarefa de mobiliar a casa é algo fácil, apesar das análises feitas pelos pesquisadores constatarem que grande parte dos espaços não comportam os mobiliários mínimos necessários para atender as 
necessidades básicas dos moradores - que muitas vezes possuem mobília de suas casas antigas e não conseguem organizá-las sem obstruir passagens ou dificultar o acesso aos outros móveis.

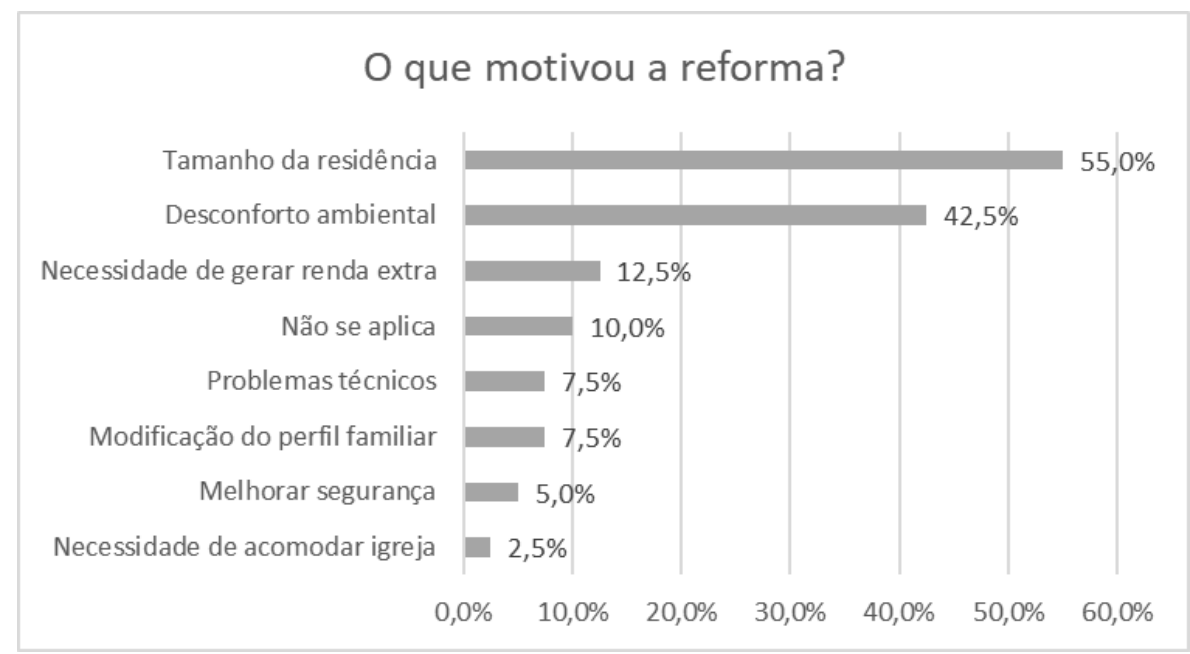

Gráfico 4 - Motivos que levaram a reforma -

Fonte: Autoras (2018)

Ainda sobre a mobília, é interessante observar algumas divergências entre o que é apresentado no projeto quanto às dimensões dos espaços e a disposição do layout básico. Como a maioria dos projetos de interesse social, o PMCMV atenta-se a reduzir ao máximo os custos, e uma das estratégias para isso é a construção de cômodos com medidas mínimas e muitas vezes insuficientes para a organização dos móveis - o que, quase sempre, significa que as edificações não atendem as exigências de desempenho de edificações habitacionais, listadas pela norma ABNT NBR - 15575:2013. Nesse sentido, foi feita uma análise para verificar se a mobília de dimensão padrão disponível no mercado consegue ser inserida nos ambientes do programa, de acordo com as tipologias de algumas lojas populares da cidade de Uberlândia.

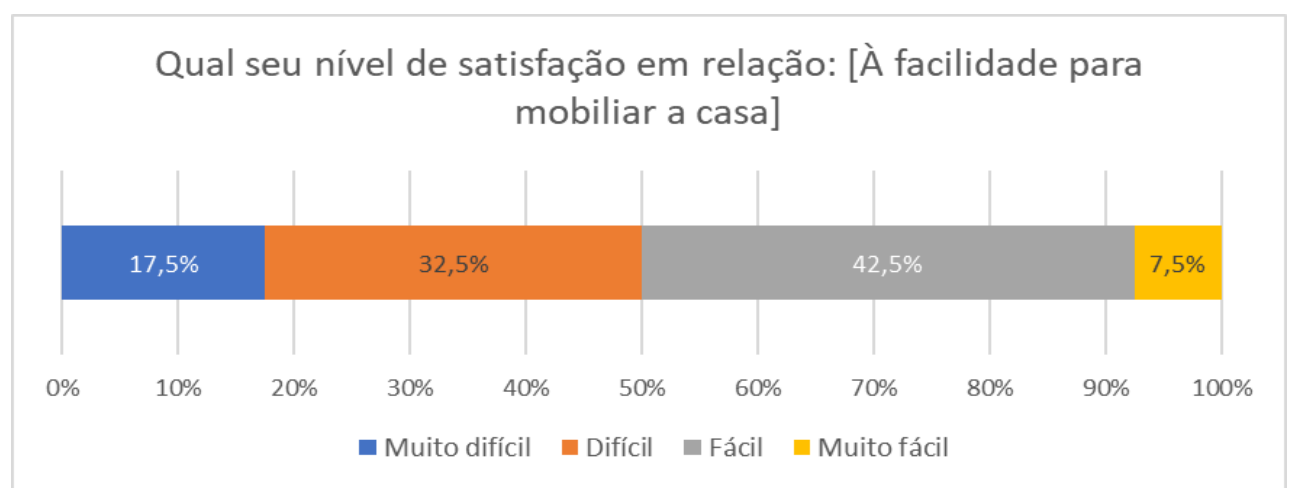

Gráfico 5 - Nível de satisfação em relação à facilidade de mobiliar a residência Fonte: Autoras (2018)

A partir das comparações, percebe-se que a maioria dos móveis obstrui a circulação dos ambientes - principalmente na sala e nos quartos. Em outras palavras, o que se é mostrado nos projetos de habitação social não condiz com a situação real dos moradores, que acabam com ambientes inutilizados por falta de espaço. Desse modo, é compreensível que as famílias busquem 
ampliar a residência para se adaptar como podem, mesmo que a estrutura e os limites rígidos da construção não facilitem tal atitude.

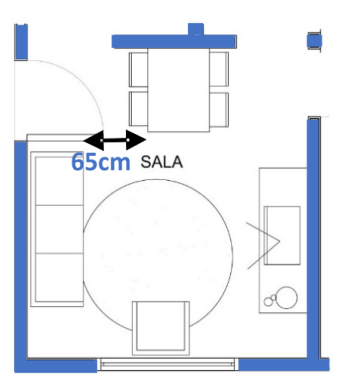

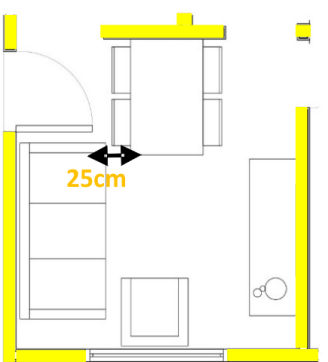

SOFÁ 3 LUGARES - $182 \times 90 \mathrm{~cm}$ POLTRONA - $70 \times 60 \mathrm{~cm}$ RACK PARA TV - 50 $\times 162 \mathrm{~cm}$ MESA 4 LIGARES - $76 \times 120 \mathrm{~cm}$ CADEIRA DE JANTAR - $48 \times 60 \mathrm{~cm}$
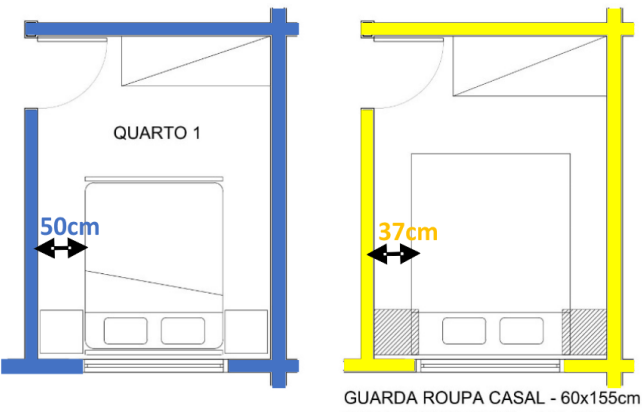
CAMA QUEEN CASAL - $160 \times 200 \mathrm{~cm}$ CRIADO MUDO $-45 \times 45 \mathrm{~cm}$

Layout sugerido pelo programa Layout compatibilizado com dimensões reais dos mobiliarios

Figura 3 - Fotomontagem: Relação projeto x realidade dos mobiliários Fonte: Autoras (2018)
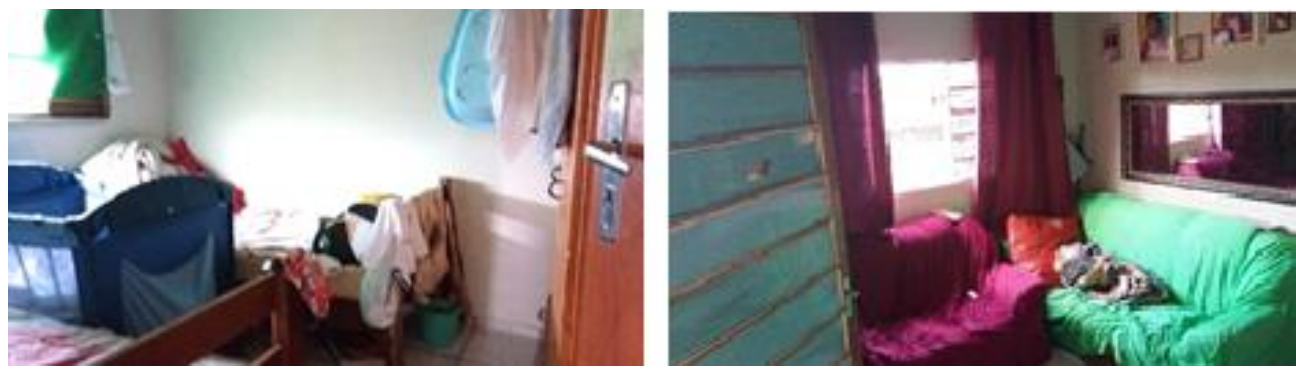

Figura 4 - Fotomontagem: Exemplos de circulação obstruída por mobiliários Fonte: Autoras (2018)

Mais especificamente sobre as ampliações, observa-se que a posição da moradia no terreno influencia diretamente nas possibilidades de expansão. Como dito anteriormente, a implantação do projeto constata as únicas áreas que permitem tal ação, que são: a parte da frente e dos fundos do terreno (Figura 5). Apesar de considerável espaço para ampliações, é notável que qualquer intervenção não estará inteiramente integrada com a tipologia padrão, uma vez que as paredes estruturais impedem grandes alterações.

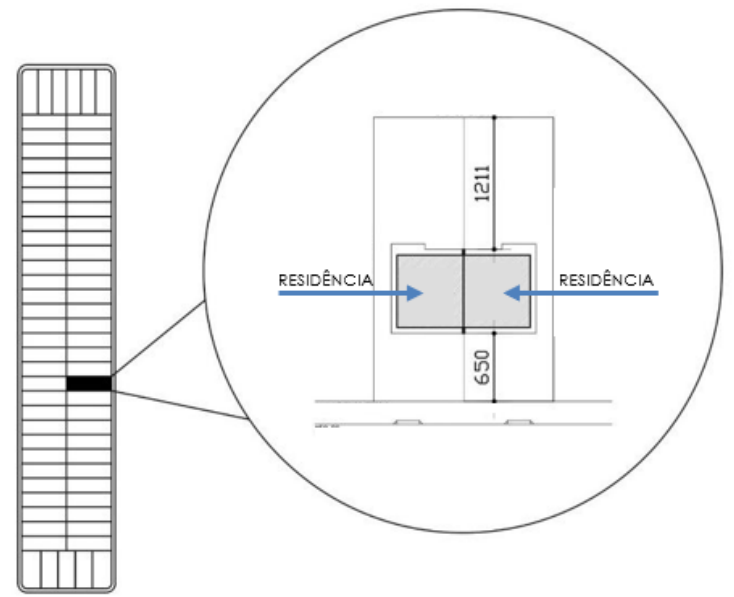

Figura 5 - Implantação da casa geminada no lote Fonte: Autoras (2018) 


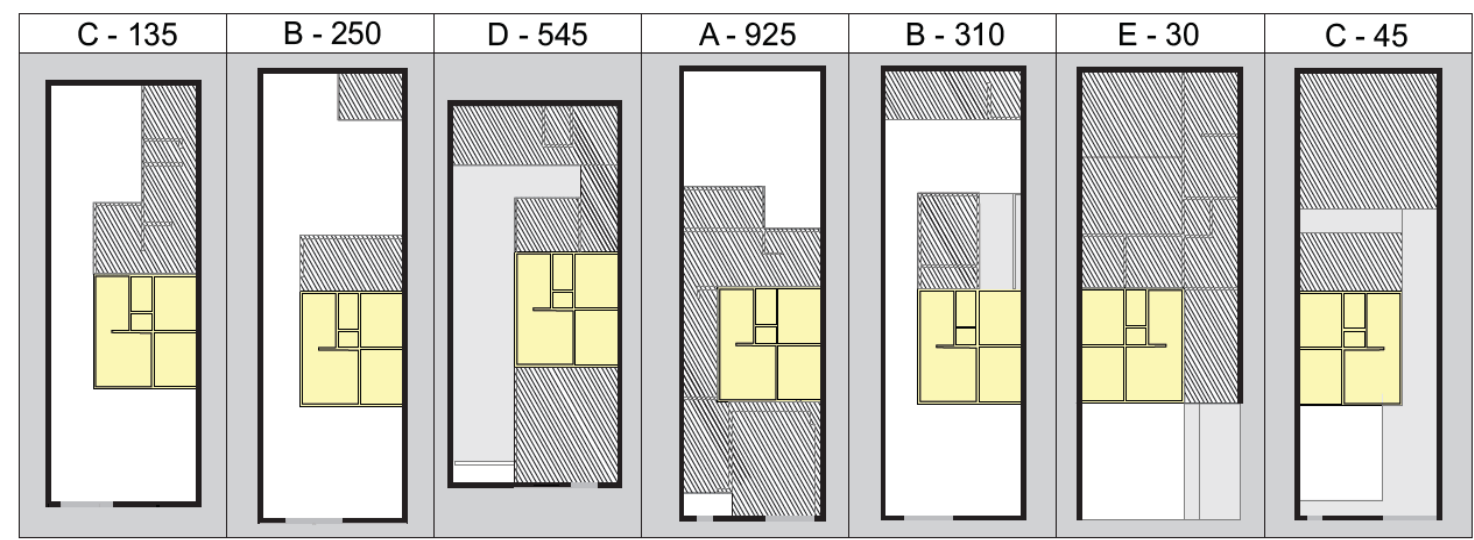

LEGENDA $\square$ TIPOLOGIA PADRÃO $\mathbb{N}$ AMPLIAÇŌES COM COBERTURA $\square$ ÁREAS PAVIMENTADAS SEM COBERTURA

Figura 6 - Relação tipologia padrão + ampliações -

Fonte: Autoras (2018)

Nesse sentido, as análises feitas no walkthrough confirmam as possíveis variações de expansão a partir do mapeamento das 7 residências selecionadas dentro do recorte do residencial. A partir do esquema abaixo, observa-se que a maioria optou pela ampliação na parte dos fundos e, como consequência da falta de planejamento prévio e da improvisação nas obras, as reformas desencadeiam diversos problemas estruturais e de organização espacial, principalmente.

A partir da definição das ampliações e dado a relevância de se observar a maneira que os moradores se adaptam de acordo com as suas necessidades, é importante analisar ainda como e onde acontecem as atividades básicas do dia a dia. Nesse sentido, o que se percebe é uma sobreposição de funções em alguns cômodos, muitas vezes por falta de espaço adequado para realizar determinada ação. Foi feito um esquema a partir da análise das 7 casas no walkthrough, que mostram situações comuns dos moradores do bairro.

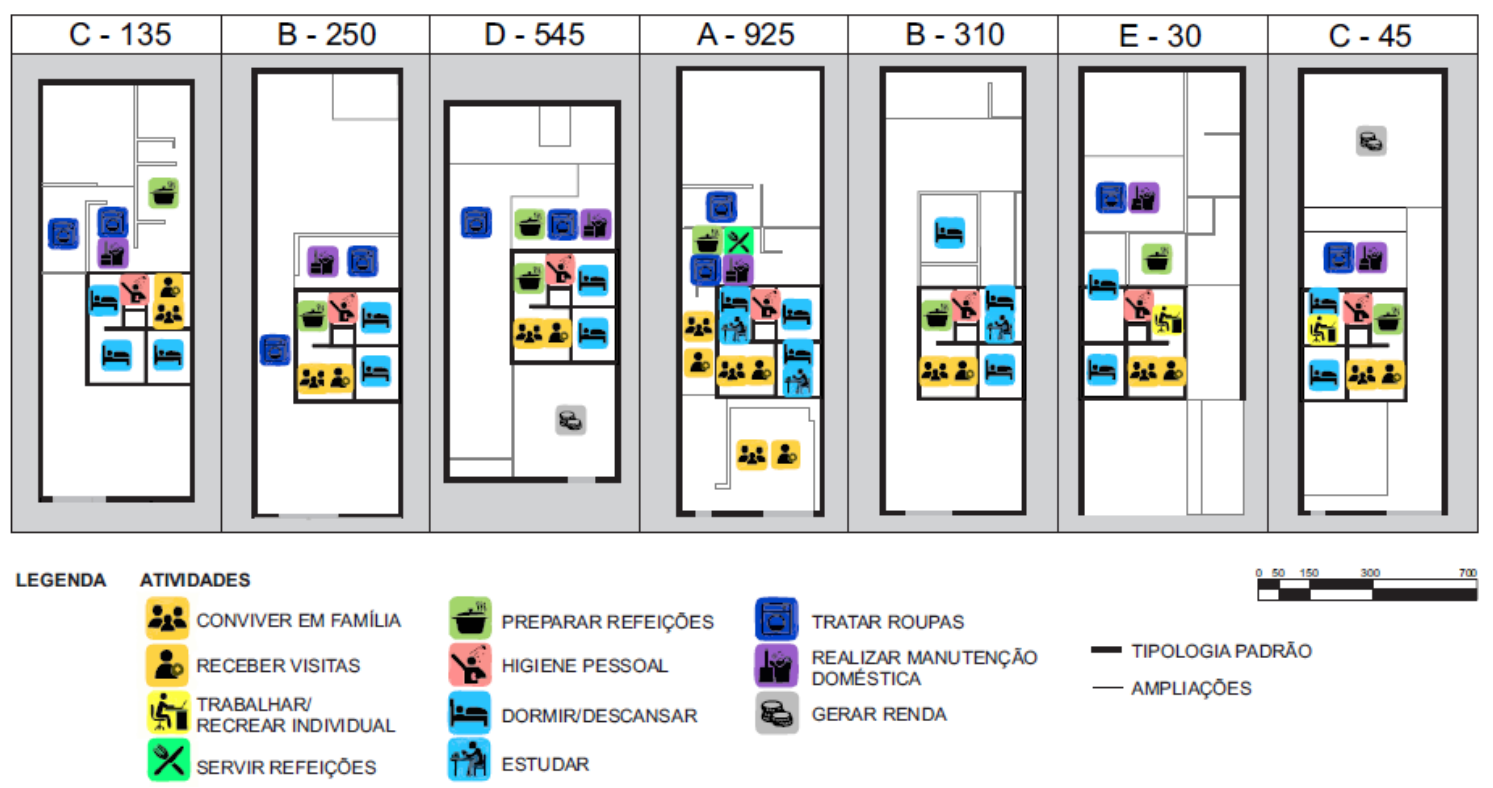

Figura 7 - Relação usos para cada cômodo -

Fonte: Autoras (2018) 

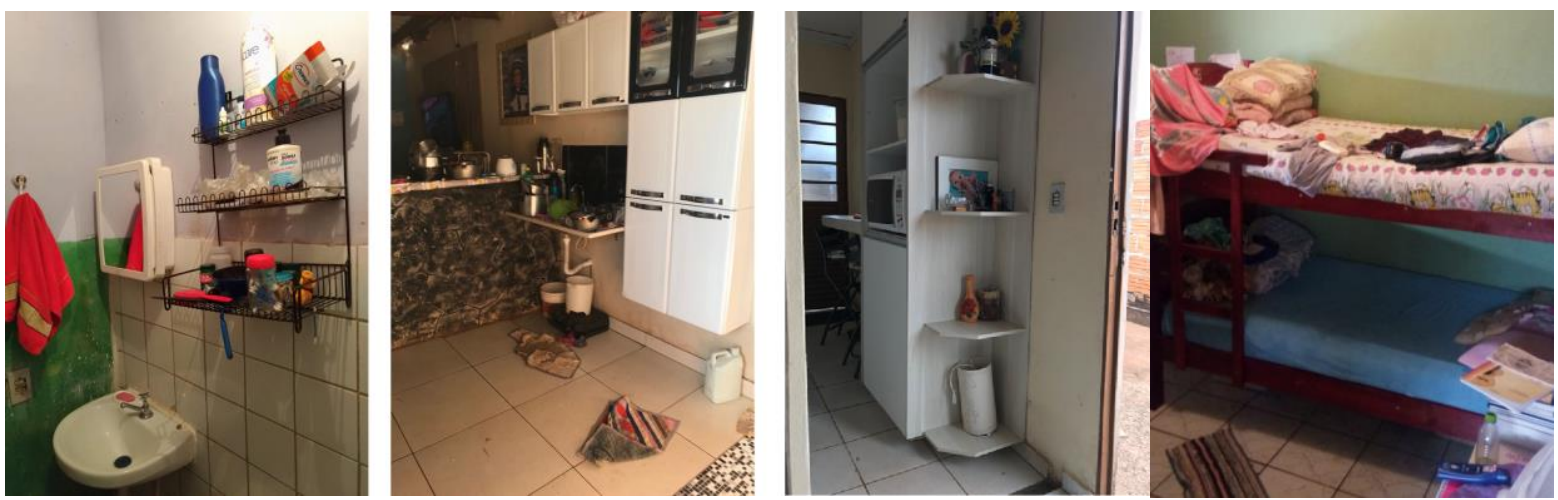

Figura 8 - Fotomontagem: Exemplos de aproveitamento dos espaços por meio de estratégias dos moradores -

Fonte: Autoras (2018)

Paralelo à todas essas questões, existe ainda uma ação bastante comum entre os moradores do residencial: muitos deles adaptam sua residência para auxiliá-los na geração de renda, seja extra ou ocupação principal. Nesses casos, eles buscam aproveitar principalmente o recuo frontal das construções para delimitar um espaço destinado ao comércio, o que pode ser explicado pelo considerável afastamento do bairro do restante da cidade, que limita os serviços disponíveis aos moradores e torna mais difícil a locomoção até um emprego - o que está diretamente relacionado à falta de acessibilidade, outro atributo importante para a conferência de resiliência.

De modo geral, é possível dizer que o problema central da falta de resiliência e adaptabilidade nas casas ofertadas pelo PMCMV se concentra na relação entre a redução dos seus espaços associado a manutenção de modelos de morar tripartidos - compartimentados e monofuncionais, que apresentam soluções de mobiliários também tradicionais. A flexibilidade, portanto, poderia ser uma resposta à ampliação da residência e adaptabilidade dessas casas, desde que fosse associada a desenhos cuja organização espacial e mobiliários otimizassem as ações domésticas.

Nesse sentido, então, apesar de estar constatado através de todas as análises citadas anteriormente a inexistência da flexibilidade no projeto padrão, existem atitudes intuitivas e criativas em diversas residências como uma tentativa de uma casa mais resiliente e adaptável. Várias casas analisadas apresentam estratégias implementadas pelos próprios moradores para tentar adaptar o espaço restrito às suas necessidades - principalmente de estocagem. Em quase todas, utilizam-se armários e estantes para aproveitar verticalmente o espaço, como mostra a figura 8. Além disso, os beliches são mobiliários usados para comportar mais pessoas nos dormitórios.

\section{CONSIDERAÇÕES FINAIS}

Em linhas gerais, percebe-se a falta de flexibilidade das residências originais do PMCMV através das análises apresentadas. O projeto dificulta modificações internas e também as ampliações realizadas inevitavelmente para o fundo ou frente das casas, pois os cômodos adicionados obstruem a iluminação e ventilação dos pré-existentes e acabam não integrados com o projeto original. As dimensões dos cômodos não levam em consideração as medidas gerais do mobiliário normalmente presente nas residências, resultando em espaços 
ainda menos funcionais e circulações interrompidas por móveis. Apesar de tudo isso, deve-se dar enfoque ao esforço geral da comunidade em desenvolver estratégias para driblar essa dificuldade de adaptação - o que constata a existência de uma flexibilidade natural (por necessidade e resiliência) capaz de amenizar o desconforto dos moradores e, principalmente, ampliar os espaços de estocagem e sobreposições. Desse modo, tendo em vista que o objetivo principal do projeto está diretamente associado com as coproduções realizadas em conjunto com a comunidade, - levantamento dos dados quantitativos e qualitativos são importantes para fomentar bancos de dados que serão utilizados posteriormente para elaborar soluções projetuais a fim de orientar os moradores e melhorar a qualidade de vida nas residências; além de servir como recomendações para projetos futuros mais resilientes e sustentáveis, que atendam de forma mais efetiva as reais necessidades da comunidade.

\section{REFERÊNCIAS}

AMORE, C. S; SHIMBO, L. Z.; RUFINO, M. B. (Org) Avaliação do Programa Minha Casa Minha Vida em seis estados brasileiros. Rio de Janeiro: Letra Capital, 2015.

ELALI, G. A.; VELOSO, M. Avaliação Pós-Ocupação e processo de concepção projetual em arquitetura: uma relação a ser melhor compreendida. In: SEMINÁRIO INTERNACIONAL NUTAU, 6., 2006, São Paulo. Anais... São Paulo: FAU-USP, 2006. CD-ROM.

LEAMAN, A.; STEVENSON, F.; BORDAS, B. Building evaluation: Practice and principles. Building Research \& Information. 38. 564-577. 10.1080/09613218.2010.495217. 2010.

MALLORY-HILL, S.; PREISER, W.; WATSON, C. Enhancing building performance. New Jersey: Wiley-Blackwell, 2012.

ONO, R.; ORNSTEIN, S. W.; VILLA, S. B.; FRANÇA, A. J. G. L. Avaliação PósOcupação na arquitetura, no Urbanismo e no Design: da Teoria à Prática. led. São Paulo: Oficina de Textos, 2018, v.1.

ORNSTEIN, S. W.; VILLA, S. B.; ONO, R. Residential high-rise buildings in São Paulo: aspects related to the adequacy to the occupant s needs. Journal of Housing and the Built Environment, p. 10.1007/s10901-1, 2010. (ONLINE)

SZÜCS, C. P. Apropriação e modificação dos espaços da casa: inventário de soluções populares. In: NUTAU, 2., 1998, São Paulo. Anais... São Paulo: FUPAM, 1998

VILLA, S. B. et al. Método de análise da resiliência e adaptabilidade em conjuntos habitacionais sociais através da avaliação pós-ocupação e coprodução. RELATÓRIO FINAL DE PESQUISA: Uberlândia: Universidade Federal de Uberlândia; Universidade de Sheffield, 2017.

VILLA, S. B. Multimétodos em avaliação-ocupação e sua adaptabilidade para o mercado imobiliário habitacional. In: VILLA, S.B.; ORNSTEIN, S.W. (Org.).

Qualidade Ambiental na habitação: avaliação pós-ocupação. 1 ed. São Paulo: Oficina de Textos, 2013, p.113-148.

VILLA, S. B; ONO, R.; FRANCA, A. J. G. L.; ORNSTEIN, S.W. Procedimentos metodológicos. In: ONO, R.; ORNSTEIN, S. W.; VILLA, S. B.; FRANÇA, A. J. G. L. 
Avaliação Pós-Ocupação na arquitetura, no Urbanismo e no Design: da Teoria à Prática. 1ed. São Paulo: Oficina de Textos, 2018, v.1, p.81-94.

VILLA, S. B.; ORNSTEIN, S. W. (Org.) Qualidade ambiental na habitação:

avaliação pós-ocupação. São Paulo: Oficina de Textos, 2013. p.359-378.

VOORDT, T. J. M. van der; WEGEN, H. B.R van. Arquitetura sob o olhar do

usuário. Programa de necessidades, projeto e avaliação de edificações. São Paulo: Editora Oficina de Textos, 2013. 237p. 